\title{
Relação entre Disclosure Ambiental e as Características Econômico-Financeiras e de Mercado das Companhias Pertencentes ao Setor de Petróleo e Gás com Atuação no Segmento de Biocombustíveis
}

\section{Relation between Environmental Disclosure and Characteristics Economic-Financial and Market Companies Belonging to the Oil and Gas Segment Performance with Biofuels}

\author{
Vivian Osmari Uhlmann \\ Mestre em Contabilidade - UFSC \\ Campus UFSC - Trindade - 88040-900 - Florianopolis, SC - Brasil - Caixa-Postal: 476 \\ viuhlmann@yahoo.com.br \\ Maíra Melo de Souza \\ Doutoranda em Administração - UFSC \\ Campus UFSC - Trindade - 88040-900 - Florianopolis, SC - Brasil - Caixa-Postal: 476 \\ mairameloufsc@gmail.com \\ Rogério João Lunkes \\ Doutor em Engenharia de Produção - UFSC \\ Professor do Departamento de Contabilidade da UFSC \\ Campus UFSC - Trindade - 88040-900 - Florianopolis, SC - Brasil - Caixa-Postal: 476 \\ lunkes@cse.ufsc.br
}

\begin{abstract}
Resumo
O objetivo desta pesquisa é relacionar o nível de disclosure ambiental com as características econômico-financeiras e de mercado das empresas pertencentes ao setor de Petróleo e Gás com atuação no segmento de biocombustíveis. Numa perspectiva de desenvolvimento sustentável é relevante vislumbrar a divulgação ambiental das empresas pertencentes a este ramo, bem como investigar se a decisão de divulgar ou não informações de caráter ambiental pode ter relação com suas características econômico-financeiras ou de mercado. A pesquisa é exploratória e a abordagem do problema é qualitativa. A amostra analisada é constituída pelas empresas classificadas no setor de biocombustíveis que publicaram demonstrações contábeis entre os anos de 2004 e 2008. Para mensurar o nível de disclosure ambiental das empresas, quantificou-se a evidenciação através de uma métrica adaptada de estudos anteriores. Desta maneira, de posse a quantidade de informações divulgada pelas empresas, verificou-se a existência de relação com suas características econômico-financeiras e de mercado. Os resultados demonstram que individualmente, ao longo dos anos, a relação do nível de disclosure ambiental com as características analisadas, das empresas pertencentes ao setor de biocombustíveis, não apresentam associação, sugerindo que a decisão de divulgar ou não informações ambientais não depende, do tamanho, rentabilidade, endividamento, empresa de auditoria ou nível de governança. Analisando comparativamente, é mister destacar que a Petrobras, que é a maior empresa da amostra, apresentou maior quantidade de divulgação ambiental, entretanto, ao olhar para as demais empresas percebe-se que a OGX em 2007, apesar de maior que a Ecodiesel apresentou menos informações ambientais, bem como a Ecodiesel apesar de menor que a PetManguinhos apresentou mais informações ambientais.
\end{abstract}

Artigo submetido em 16 de fevereiro de 2011 e aceito em 03 de junho de 2011 pelo Editor Marcelo Alvaro da Silva Macedo, após double blind review. 
Palavras-chave: Disclosure (Evidenciação) ambiental. Características. Setor de Bicombustíveis.

\begin{abstract}
The objective of this research is to relate the level of disclosure with the environmental characteristics and economic-financial companies in the market for oil and gas industry with operations in the biofuel segment. From the perspective of sustainable development is relevant to discern environmental disclosure for companies in this industry as well as the decision to investigate whether or not to disclose information on environmental may be related to its economic-financial or market. The research is exploratory and qualitative approach to the problem is. The sample consists of the ranked companies in the biofuels industry that published financial statements between 2004 and 2008. To measure the level of corporate environmental disclosure, the disclosure was quantified by a measure adapted from previous studies. Thus, possession of the amount of information disclosed by companies, we verified the existence of a relationship with their economic-financial and market conditions. The results show that individually over the years, the relationship between the level of environmental disclosure to the characteristics analyzed, for companies in the biofuels sector, have no association, suggesting that the decision to disclose environmental information or not does not depend on the size, profitability, leverage, audit firm or level of governance. Comparatively analyzing, we must point out that Petrobras, the largest company in the sample showed the greatest amount of environmental disclosure, however, to look for other companies realize that OGX in 2007, although higher than the Ecodiesel had less environmental information, as well as Ecodiesel although smaller than the PetManguinhos had more environmental information.
\end{abstract}

Keywords: Disclosure environment. Characteristics. Biofuels sector.

\title{
1. Introdução
}

A sociedade tem pressionado o setor privado a assumir sua responsabilidade pelos impactos decorrentes de suas atividades no meio ambiente (HACKSTON; MILNE, 1996). Para Nossa (2002), "além da ênfase dimensionada com a preservação e recuperação ambiental, as empresas devem estar aptas a informar aos seus stakeholders suas atividades e desempenhos ambientais".

Nesta linha de raciocínio, Farias e Ribeiro (2009, p. 2) entendem que "a melhora no desempenho ambiental tende a afetar a política de divulgação ambiental, no intuito de demonstrar aos stakeholders suas intenções e iniciativas para evitar a degradação do meio ambiente e afetar positivamente na sua avaliação". Na concepção de Gray e Bebbington (2001), a confiança dos stakeholders é um fator de relevância na decisão da política de divulgação das empresas.

A divulgação reduz possíveis assimetrias de informação entre as empresas e seus stakeholders. Muitas delas estão divulgando suas estratégias ambientais voluntariamente, e esta posição tem sido objeto de uma crescente literatura conceitual (BRAMMER; PAVELIN, 2008).

Várias pesquisas foram realizadas buscando vislumbrar o tema disclosure ambiental e/ou social praticado pelas empresas (GRAY; KOUHY; LAVERS, 1995; CAMPBELL, 2003; BROWN, 2007; BRAMMER; PAVELIN, 2008; KOLK; PEREGO, 2008; STANNY; ELY, 2008; KOLK; PINKSE, 2009; KAENZIG et al., 2009; SPENCE, 2009; CHO; ROBERTS; PATTEN, 2009). No âmbito nacional, o assunto também tem recebido a atenção de diversos 
pesquisadores, dentre eles: Nossa (2002); Lima (2007); Calixto, Barbosa e Lima (2007); Murcia et al. (2008); Rover, Murcia e Borba (2009); Farias e Ribeiro (2009).

A sustentabilidade ambiental visa aperfeiçoar a utilização dos recursos naturais para atender às necessidades presentes, protegendo-os de modo a garantir sua existência para gerações futuras (BROWN, 2007). Muitas empresas são chamadas a contribuir efetivamente com o desenvolvimento sustentável das sociedades em que operam. O principal desafio, neste contexto, é integrar e conciliar o econômico com a questão ambiental e social (HAHN; SCHEERMESSER, 2006). Nesta linha de pensamento, é relevante estudar a evidenciação ambiental em empresas do ramo de gás e petróleo, visto que estas atuam justamente na perspectiva do desenvolvimento sustentável.

Com base no exposto elaborou-se o seguinte problema de pesquisa: qual a relação entre o nível de nível de disclosure ambiental e as características econômico-financeiras e de mercado das empresas pertencentes ao setor de petróleo e gás com atuação no segmento de biocombustíveis? Para responder o problema de pesquisa, este estudo tem como objetivo relacionar o nível de disclosure ambiental com as características econômico-financeiras e de mercado das empresas pertencentes ao setor de Petróleo e Gás com atuação no segmento de biocombustíveis.

Optou-se, assim, por estruturar o presente trabalho em três partes distintas, além desta introdução e das considerações finais. Na primeira delas, apresenta-se um panorama sobre a evidenciação ambiental; na segunda, descreve-se a estrutura conceitual adotada para a análise das informações ambientais evidenciadas pelas companhias pesquisadas; finalizando-se por, na terceira seção, demonstrar a relação percebida entre o disclosure e as características das empresas, cotejando apenas um setor.

\section{Revisão da Literatura}

O crescente debate acerca da redução na emissão dos gases que causam a intensificação do efeito estufa faz com que as empresas, direta ou indiretamente, envolvidas comecem a sofrer maiores pressões públicas no que diz respeito à busca de novas fontes renováveis de energia (UHLMANN; SOUZA e LUNKES, 2010), e neste contexto o disclosure (evidenciação/divulgação) de informações relacionadas aos impactos ambientais relacionados as atividades da empresa torna-se relevante, bem como a informação concernente ao o que ela faz para contornar tal situação.

A finalidade da evidenciação (disclosure) é apresentar ao usuário a real situação financeira e patrimonial de uma entidade (IUDICIBUS, 2009). Desta maneira, na visão do usuário externo, a falta de divulgação por parte destas empresas poderia gerar uma situação de desconfiança. E neste contexto, é mister salientar que a divulgação de informações ambientais não limita-se apenas as boas notícias (LIMA, 2007). A este respeito, Cho, Roberts e Patten (2009) salientam que os gestores podem utilizar a divulgação ambiental para melhorar a sua imagem no mercado.

Para Farias e Ribeiro (2009), a melhora no desempenho ambiental tende a afetar a política de divulgação ambiental, no intuito de demonstrar aos stakeholders suas intenções e iniciativas para evitar a degradação do meio ambiente e afetar positivamente na sua avaliação. Lev (1992) e Botosan (1997) sugerem que melhores práticas de disclosure ambiental podem ter associação com o baixo custo de capital.

Às organizações inseridas no mercado de energia renovável estende-se a recomendação do Código das Melhores Práticas de Governança Corporativa (2009, p. 19) de "incorporar considerações de ordem social e ambiental na definição dos negócios e operações". Tais informações ambientais, juntamente com os eventos e transações específicos da atividade, necessitam ser devidamente reconhecidos e evidenciados pelas empresas, em 
face da crescente cobrança da sociedade por uma forma de gestão dos recursos aliada a uma conduta ambientalmente responsável.

A gestão da informação nas organizações tem como foco o público interno e externo, além dos vários meios de tratar e distribuir as informações estratégicas empresariais, conforme mencionam Calixto, Barbosa e Lima (2007).

Nesse contexto, a Contabilidade, principal sistema de informação da empresa, dispõe de vários instrumentos de divulgação capazes de elucidar a informação contábil a todos os usuários, dentre os quais se destacam: o Relatório Anual, o Relatório de Sustentabilidade, o Relatório da Administração, as Demonstrações Contábeis e as Notas explicativas.

Tendo em vista as demonstrações contábeis, Ribeiro, Nascimento e Van Bellen (2009) constataram que as notas explicativas foram as preferidas das empresas pertencentes aos setores de água e saneamento, petróleo e siderurgia, com ações listadas nas bolsas de valores do Brasil, dos Estados Unidos e da Inglaterra, para a evidenciação das informações ambientais. Ainda, segundo os autores, as empresas analisadas utilizaram a parte textual do relatório anual para mostrar os seus investimentos no meio ambiente, e as demonstrações contábeis para informar sobre os seus litígios ou passivos ambientais. E, quanto ao tipo de informação mais evidenciada, houve um equilíbrio entre informações econômicas e outras informações ambientais.

O trabalho de Rover, Borba e Murcia (2009) objetivou identificar as características do disclosure voluntário ambiental de empresas brasileiras pertencentes a setores de alto impacto ambiental, compreendendo a classificação de evidência, o tipo de notícia, a referência temporal e a localização das informações. Os resultados da pesquisa demonstraram que, no período de 2005 a 2007, as empresas da amostra evidenciaram 6.182 sentenças ambientais, sendo $73 \%$ divulgadas nos Relatórios de Sustentabilidade (RS), e 27\% nas Demonstrações Financeiras Padronizadas (DFPs). Também foi possível verificar no estudo que a maior parte da evidenciação é declarativa, do tipo positiva e com referência temporal não especificada.

Em pesquisa semelhante, só que aplicada em empresas produtoras de etanol com ações listadas na BOVESPA e NYSE, Vellani (2009) pôde constatar que: (i) elas evidenciaram informações ambientais por meio de textos escritos e não financeiros contidos nos relatórios contábeis enviados à CVM e SEC; (ii) os valores dos gastos e benefícios ambientais não foram citados por completo; (iii) houve um padrão na evidenciação, mas ainda em evolução; (iv) elas ainda informam somente o exigido por leis e órgãos fiscalizadores; e (v) não foram encontradas evidências de relatórios econômico-financeiro-ambientais.

\section{Metodologia}

\subsection{Enquadramento Metodológico e Seleção da Amostra}

No que compete aos objetivos, o estudo enquadra-se como exploratório-descritivo. E a abordagem é predominantemente qualitativa. A amostra de pesquisa foi constituída pelas empresas de capital aberto listadas na Bolsa de Valores de São Paulo (BOVESPA), pertencentes ao setor de petróleo, gás natural e biocombustíveis, que publicaram DFPs no período de 2004 a 2008.

A escolha da amostra foi intencional, que conforme Richardson (2008), o pesquisador escolhe mediante a interação das características das empresas com os objetivos da pesquisa. Diante disso, foi possível selecionar quatro empresas.

\subsection{Procedimentos de Coleta e Tratamento dos Dados}

A obtenção dos dados foi por meio das Notas Explicativas e Relatório da Administração arquivados no site da Bovespa. Para quantificar o nível de disclosure ambiental das empresas, o estudo teve como base uma adaptação da estrutura conceitual Uhlmann, V. O.; Souza, M. M.; Lunkes, R. J. 
utilizada nos trabalhos de Gray, Kouhy e Lavers (1995), Nossa (2002), Rover (2009), Rover, Borba e Murcia (2009), Lima (2007), Murcia et al. (2008). A estrutura conceitual adotada na pesquisa é composta de 8 categorias e 42 subcategorias. As subcategorias se constituem em sentenças ambientais objetivando retratar as informações buscadas nos relatórios pesquisados, servindo de unidades de registro. O Quadro 1 apresenta a referida estrutura conceitual.

\begin{tabular}{|c|c|}
\hline CATEGORIAS & SUBCATEGORIAS \\
\hline \multirow{5}{*}{ 1. Políticas Ambientais } & Declaração das políticas/práticas/ações atuais e futuras \\
\hline & Estabelecimento de metas e objetivos ambientais \\
\hline & $\begin{array}{l}\text { Declarações indicando que a empresa está (ou não) em obediência } \\
\text { (compliance) com as leis, licenças, normas e órgãos ambientais }\end{array}$ \\
\hline & Parcerias ambientais \\
\hline & Prêmios e participações em índices ambientais \\
\hline \multirow{3}{*}{$\begin{array}{l}\text { 2. Sistemas de gerenciamento } \\
\text { ambiental }\end{array}$} & ISO 14.000 \\
\hline & Auditoria ambiental \\
\hline & Gestão ambiental \\
\hline \multirow{11}{*}{$\begin{array}{l}\text { 3. Impactos dos produtos e } \\
\text { processos no meio ambiente }\end{array}$} & Resíduos/desperdícios \\
\hline & Processo de acondicionamento (embalagem) \\
\hline & Reciclagem \\
\hline & Desenvolvimento de produtos ecológicos \\
\hline & Impacto na área de terra utilizada \\
\hline & Riscos ambientais \\
\hline & Uso eficiente/reutilização da água/tratamento de efluentes \\
\hline & Vazamentos/derramamentos \\
\hline & Danos ambientais \\
\hline & Recuperação ambiental \\
\hline & Prevenção/proteção ambiental \\
\hline \multirow{6}{*}{ 4. Energia } & Conservação e/ou utilização mais eficiente nas operações \\
\hline & Utilização de materiais desperdiçados na produção de energia \\
\hline & Discussão sobre a preocupação com a possível falta de energia \\
\hline & Desenvolvimento/exploração de fontes de energia renováveis \\
\hline & Pesquisa/desenvolvimento de tecnologias ambientais \\
\hline & Biocombustíveis/biodisel/etanol \\
\hline \multirow{7}{*}{$\begin{array}{l}\text { 5. Informações financeiras } \\
\text { ambientais }\end{array}$} & Investimentos ambientais \\
\hline & Custos/despesas ambientais \\
\hline & Passivos ambientais \\
\hline & Provisões/contingências ambientais \\
\hline & Práticas contábeis ambientais \\
\hline & Seguro ambiental \\
\hline & Ativos ambientais tangíveis e intangíveis \\
\hline \multirow{2}{*}{ 6. Educação e pesquisa ambiental } & Educação ambiental (internamente e/ou comunidade) \\
\hline & Pesquisas relacionadas ao meio ambiente \\
\hline \multirow{4}{*}{ 7. Mercado de créditos de carbono } & Projetos de Mecanismo de Desenvolvimento Limpo (MDL) \\
\hline & Créditos de Carbono \\
\hline & Gases do Efeito Estufa (GEE)/Emissões atmosféricas \\
\hline & Certificados de Emissões Reduzidas (CER) \\
\hline \multirow{5}{*}{ 8. Outras informações ambientais } & $\begin{array}{l}\text { Menção sobre sustentabilidade/desenvolvimento } \\
\text { sustentável/responsabilidade socioambiental }\end{array}$ \\
\hline & Gerenciamento de florestas/reflorestamento \\
\hline & Conservação da biodiversidade \\
\hline & Paisagismo e jardinagem (landscaping) \\
\hline & Relacionamento com stakeholders \\
\hline
\end{tabular}

Fonte: Adaptada de Gray, Kouhy e Lavers (1995); Nossa (2002); Rover, (2009); Rover, Borba e Murcia, (2009); Lima (2007); Murcia et al. (2008). 
No tratamento dos dados, foi utilizada a técnica de análise de conteúdo, que se procedeu com a quantificação das informações ambientais identificadas cada qual na respectiva categoria. Assim, atribuiu-se 1 ponto para cada item divulgado.

No que tange ao tipo de notícia: Gray, Kouhy e Lavers (1995) sugerem o uso de três critérios para a classificação das informações sobre o meio ambiente: informação boa declarações que reflitam crédito para a companhia; informação ruim - declarações que reflitam descrédito para a companhia; informação neutra - declarações cujo crédito/descrédito para a empresa não é claro.

Após a obtenção da quantidade de informações ambientais divulgada em cada empresa realizou-se a comparação com suas respectivas características econômico-financeiras e de mercado. O Quadro 2 apresenta as características utilizadas nesta pesquisa, bem como as suas respectivas proxies.

Quadro 2: Características e Proxies Utilizadas na Pesquisa
\begin{tabular}{|l|l|}
\hline \multicolumn{1}{|c|}{ Variável } & \multicolumn{1}{c|}{ Proxy } \\
\hline Tamanho & Total do Ativo \\
\hline Rentabilidade & Rentabilidade do Ativo (ROA) \\
\hline Endividamento & Endividamento Total \\
\hline Auditoria & Classificada em Big Four ou outras \\
\hline Nível Governança & Adota Nível Diferenciado ou não \\
\hline
\end{tabular}

No que compete ao tamanho da empresa, Hossain (2008) defende que gestores de empresas maiores possuem mais razões para acreditar nos benefícios do disclosure voluntário. No que diz respeito a rentabilidade, Lang e Lundholm (1993) e Akerlof (1970), objetivando uma diferenciação entre as outras companhias existentes no mercado, os administradores de empresas mais rentáveis teriam um incentivo para realização de disclosure voluntário de informações.

Em relação ao endividamento, supõe-se que empresas mais endividadas acreditem que através do disclosure voluntário possam ganhar mais credibilidade do mercado, desta forma, sugere-se uma possível relação entre nível de disclosure ambiental e endividamento.

Em relação à adoção de nível diferenciado de governança, de acordo com Leuz (2006) países com fracos mecanismos de proteção aos acionistas possuem maior dificuldade de obtenção de financiamentos, nesta lógica a transparência através do diclosure ganha relevância.

O grupo de empresas de auditoria conhecidas por 'Big Four' corresponde as maiores empresas de auditoria do mundo, este conjunto é formado pelas empresas: PricewaterhouseCoopers; KPMG; Deloitte Touche Tohmatsu e Ernst \& Young. Desta meneira, acredita-se que um melhor nível de disclosure ambiental possa ter relação com a empresa de auditoria externa.

\section{Descrição e Análise dos Resultados}

A fim de verificar o nível de disclosure ambiental, bem como a localização da informação ambiental, o Quadro 3 apresenta a quantidade de informações encontrada nas empresas.

Os anos que estão destacados nas empresas Ecodiesel e OGX referem-se ao período em que elas não arquivaram DFPs na BOVESPA. Percebe-se que a empresa Petrobras foi a que mais divulgou informações de caráter ambiental no período de 2004 a 2008. Nas empresas Ecodiesel e PetManguinhos também notou-se, embora em menor proporção, uma certa preocupação em evidenciar informações de natureza ambiental. Já na empresa OGX, constituída em 2006, é possível perceber que a política de evidenciação ambiental não teve Uhlmann, V. O.; Souza, M. M.; Lunkes, R. J. 
prioridade nos anos pesquisados. Os próximos tópicos apresentaram a análise dos dados concernente a cada empresa da amostra, para no final realizar as discussões gerais acerca dos resultados.

\begin{tabular}{|c|c|c|c|c|c|c|c|c|c|c|c|c|c|c|c|}
\hline \multirow{2}{*}{$\begin{array}{l}\text { Ano } \\
\text { Empresas }\end{array}$} & \multicolumn{2}{|c|}{2004} & \multirow[b]{2}{*}{ Total } & \multicolumn{2}{|c|}{2005} & \multirow{2}{*}{ Total } & \multicolumn{2}{|c|}{2006} & \multirow{2}{*}{ Total } & \multicolumn{2}{|c|}{2007} & \multirow{2}{*}{ Total } & \multicolumn{2}{|c|}{2008} & \multirow{2}{*}{ Total } \\
\hline & NE & RA & & NE & $\mathbf{R A}$ & & NE & $\mathbf{R A}$ & & NE & RA & & NE & RA & \\
\hline Ecodiesel & & & $\mathbf{0}$ & 11 & 20 & 31 & 21 & 33 & 54 & 16 & 29 & 45 & 18 & 13 & 31 \\
\hline Petrobras & 21 & 49 & 70 & 13 & 47 & 60 & 13 & 45 & 58 & 9 & 67 & 76 & 13 & 50 & 63 \\
\hline OGX & & & & & & & 0 & 0 & $\mathbf{0}$ & 0 & 2 & 2 & 1 & 5 & 6 \\
\hline PetManguinhos & 4 & 9 & 13 & 5 & 12 & 17 & 5 & 15 & 20 & 4 & 8 & 12 & 4 & 5 & 9 \\
\hline
\end{tabular}

Fonte: Elaborado pelos autores com base nos dados da pesquisa

Legenda: RA - Relatório da Administração; NE - Notas Explicativas

Quanto ao tipo de informação divulgada, a Figura 1 apresenta os resultados encontrados nas empresas, em todos os anos pesquisados, de uma maneira geral.

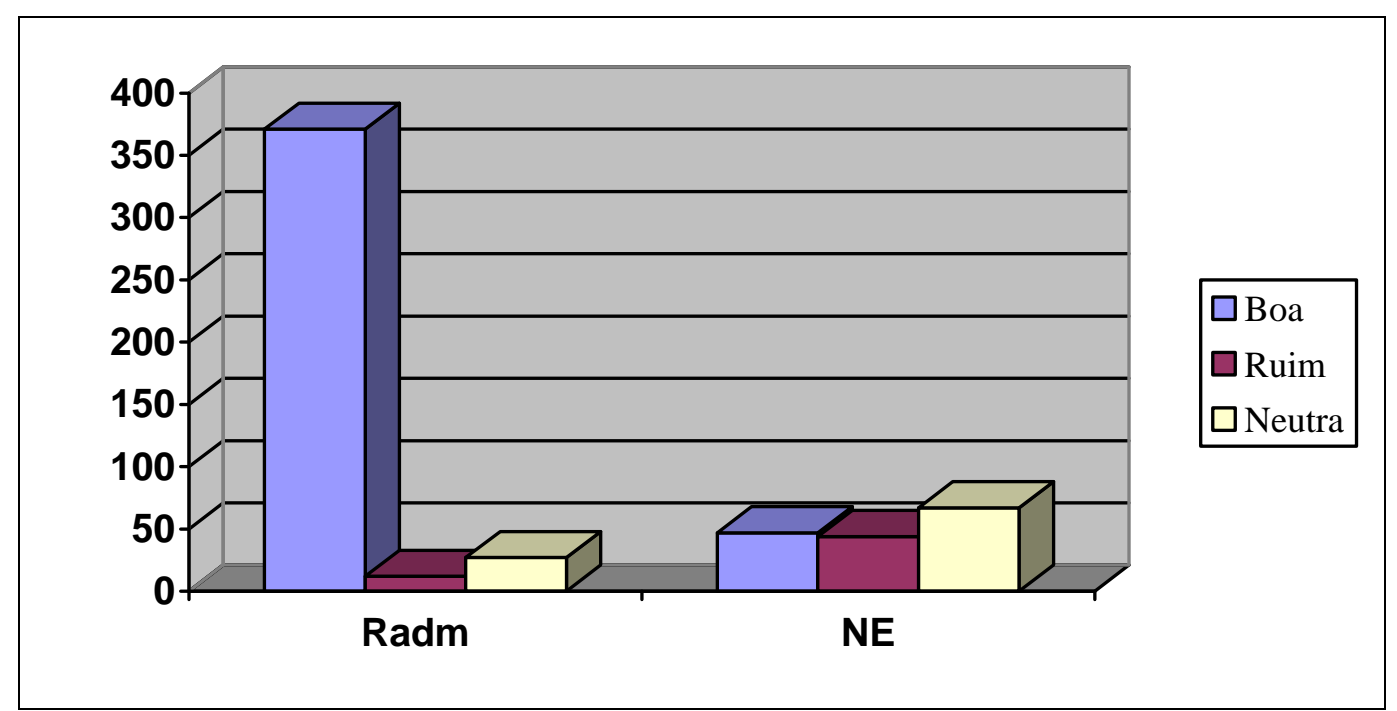

Figura 1: Classificação das informações ambientais quanto ao tipo de notícia nas DFPs Fonte: Resultados da pesquisa (2010)

Legenda: Radm - Relatório da Administração; NE - Notas Explicativas

Percebe-se na Figura 1 que grande parte $(88,8 \%)$ das informações ambientais classificadas como do tipo boa encontra-se evidenciada no Relatório da Administração, embora também tenham sido verificadas, em menor proporção, informações neutras e ruins.

Já as Notas Explicativas agregam a maioria das informações neutras e ruins decorrentes das atividades fins da empresa.

Os próximos tópicos agregam os resultados por empresa.

\subsection{Empresa Ecodiesel - Relação do Nível de Disclosure com suas Características Econômico-Financeiras e de Mercado}

O Quadro 4 apresenta as informações concernentes ao nível de disclosure ambiental e algumas características econômico-financeiras e de mercado empresa Ecodiesel. 
Quadro 4: Informações Disclosure e Características Empresa Ecodiesel

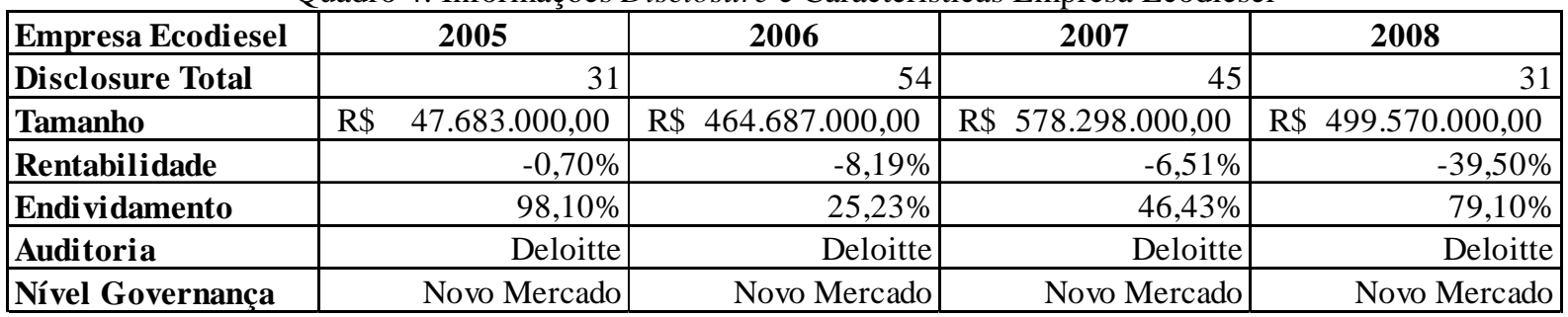

Fonte: Elaborado pelos autores com base nos dados da pesquisa.

É possível perceber que o crescimento mais significativo no nível de disclosure foi entre 2006 e 2005 (De 31 para 54). No ano de 2006 quando houve uma redução na rentabilidade ocorreu um aumento no disclosure, contudo em 2008 quando a rentabilidade reduziu fortemente o disclosure ficou em 31. O que é possível extrair deste fato é que a rentabilidade não parece ser fator relacionado ao disclosure ambiental praticado nesta empresa.

Em relação ao endividamento, apesar de não demonstrar uma relação consistente com o nível de disclosure ambiental, é mister destacar que os menores níveis de evidenciação verificados foram nos anos que apresentaram maior grau de endividamento (2005 e 2008).

Em relação as variáveis auditoria e nível de governança, não percebe-se relação com o nível de disclosure ambiental praticado pela Ecodiesel, pois continuaram constantes ao longo dos anos, enquanto o nível de evidenciação se alterou, muito embora.

O tamanho (Total do Ativo) da empresa apresentou relevante aumento em 2006, período em que o disclosure também demonstrou aumento, todavia, em 2007 quando o valor do ativo teve mais um aumento o disclosure foi menor, o que sugere que, nesta empresa, o tamanho não possui relação com o nível de evidenciação ambiental.

\subsection{Empresa Petrobras - Relação do Nível de Disclosure com suas Características Econômico-Financeiras e de Mercado}

O Quadro 5 demonstra as informações referentes ao nível de disclosure ambiental e algumas características econômico-financeiras e de mercado da empresa Petrobras.

Quadro 5: Informações Disclosure e Características Empresa Petrobras

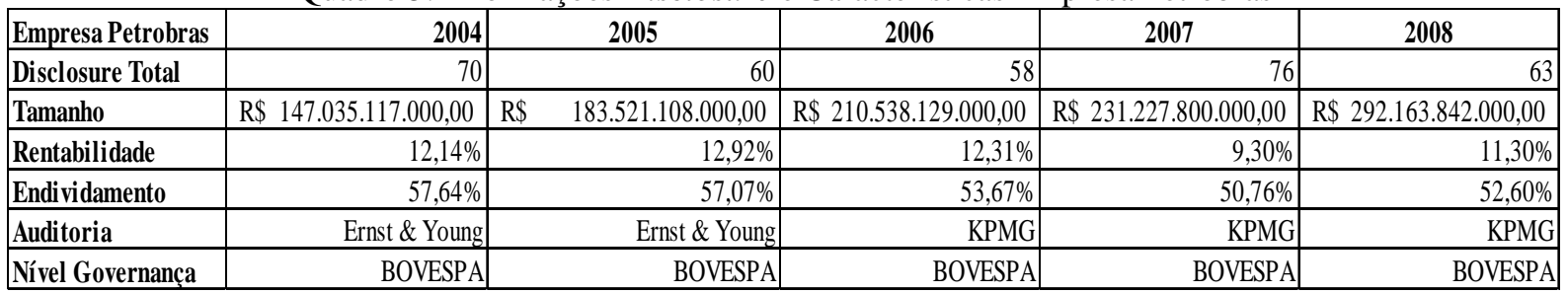

Fonte: Elaborado pelos autores com base nos dados da pesquisa.

É notável que a Petrobras possui um nível maior de disclosure ambiental comparativamente as outras empresas do setor, conforme já apontado no Quadro 2. Ressaltase também que o tamanho desta empresa é muito superior ao das outras pertencentes a este setor. Este fato talvez seja um indicativo que as empresas maiores possuem um maior nível de divulgação ambiental se comparadas às empresas menores. Entretanto, é mister salientar que analisando a Petrobras individualmente, ao longo dos anos observados, o aumento no seu tamanho não acarretou em aumento em seu disclosure ambiental, bem como observado também na empresa Ecodiesel.

Em relação à rentabilidade, verifica-se que o nível mais alto de divulgação ocorreu justamente quando a rentabilidade caiu 3.01\% em 2007, contudo nos outros anos enquanto os 
níveis de disclosure foram diversos a rentabilidade praticamente manteve-se estável (entre 2004 e 2006). O que sugere que a rentabilidade não pode ser considerada fator determinante no que tange a evidenciação ambiental da Petrobras.

Em relação ao endividamento, também não se constata uma relação com a evidenciação ambiental. Destaca-se que em todos os anos a empresa foi auditada por uma Big Four e não adotou qualquer nível diferenciado de governança. $\mathrm{O}$ que sugere que mesmo comparativamente as outras empresas do setor a adoção de nível diferenciado de governança não é fator determinante para o disclosure ambiental, visto que a empresa com maior quantidade de evidenciação de informações não adota qualquer nível diferenciado de governança.

\subsection{Empresa OGX - Relação do Nível de Disclosure com suas Características Econômico-Financeiras e de Mercado}

O Quadro 6 traz as informações que dizem respeito ao nível de disclosure ambiental e algumas características econômico-financeiras e de mercado da empresa OGX.

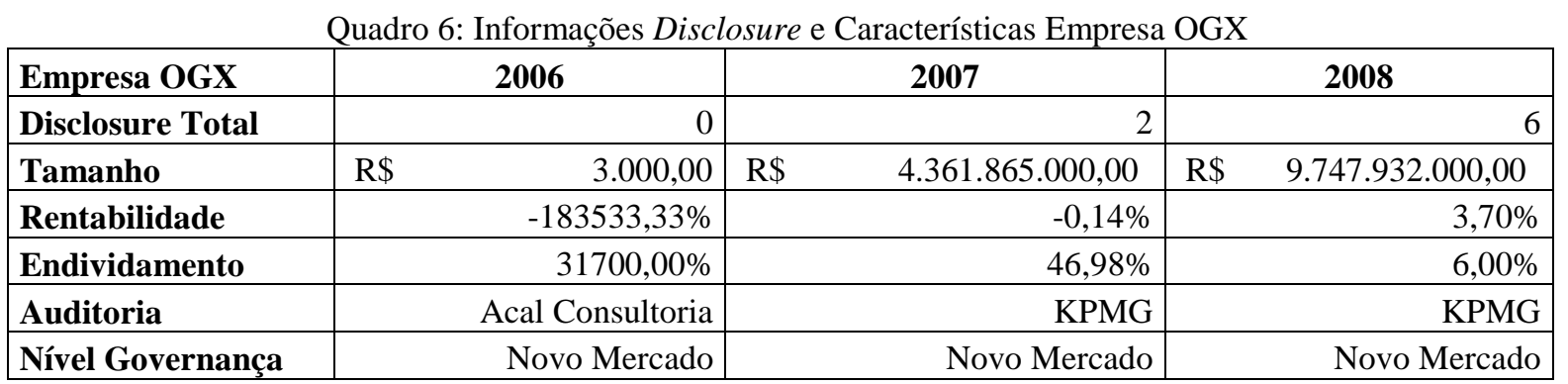

Fonte: Elaborado pelos autores com base nos dados da pesquisa.

A empresa OGX foi constituída em 2006, sendo a empresa que apresentou menor quantidade de informações ambientais, comparativamente as outras empresas do setor. Em seu primeiro exercício social não apresentou informações ambientais e nos demais, apesar de ter divulgado alguma informação, a quantidade foi muito pequena.

Percebe-se que mesmo a partir de seu segundo exercício social, em que seus indicadores começaram a apresentar melhora, a evolução do disclosure ambiental não acompanhou o progresso em igual proporção, o que sugere que, individualmente na empresa, o tamanho, rentabilidade e endividamento não demonstram ter relação com a quantidade de disclosure ambiental.

A Governança Corporativa, conforme já observado nas outras empresas, não demonstra ser significativa para explicar o disclosure ambiental, visto que, mesmo a empresa OGX sendo pertencente ao novo mercado seu disclosure pode ser considerado baixo.

A partir de 2007 a empresa começou a ser auditada por empresa de auditoria Big Four, contudo conforme já destacado o aumento no disclosure foi muito pequeno.

\subsection{Empresa PetManguinhos - Relação do Nível de Disclosure com suas Características Econômico-Financeiras e de Mercado}

O Quadro 7 demonstra as informações concernentes ao nível de disclosure ambiental e algumas características econômico-financeiras e de mercado da empresa PetManguinhos. 
Quadro 7: Informações Disclosure e Características Empresa PetManguinhos

\begin{tabular}{|l|r|r|r|r|r|}
\hline Empresa PetManguinhos & $\mathbf{2 0 0 4}$ & $\mathbf{2 0 0 5}$ & $\mathbf{2 0 0 6}$ & $\mathbf{2 0 0 7}$ & $\mathbf{2 0 0 8}$ \\
\hline Disclosure Total & 13 & 17 & 20 & 12 & 9 \\
\hline Tamanho & $\mathrm{R} \$ 360.247 .000,00$ & $\mathrm{R} \$ 235.879 .000,00$ & $\mathrm{R} \$ 252.992 .000,00$ & $\mathrm{R} \$ 248.683 .000,00$ & $\mathrm{R} \$ 152.032 .000,00$ \\
\hline Rentabilidade & $5,25 \%$ & $-49,79 \%$ & $-9,05 \%$ & $-10,69 \%$ & $-253,00 \%$ \\
\hline Endividamento & $45,55 \%$ & $64,96 \%$ & $76,38 \%$ & $86,67 \%$ & $331,30 \%$ \\
\hline Auditoria & Deloitte & Deloitte & Deloitte & Pricewaterhouse & BDO Trevisan \\
\hline Nível Governança & Bovespa & Bovespa & Bovespa & Bovespa & Bovespa \\
\hline
\end{tabular}

Fonte: Elaborado pelos autores com base nos dados da pesquisa.

Em quantidade de disclosure ambiental, a empresa PetManguinhos ficou em terceiro lugar, em relação as demais empresas. Em 2008 nota-se que seus indicadores de rentabilidade e endividamento tiveram uma piora considerável. Percebe-se que a empresa passou por uma instabilidade econômica-financeira no período verificado, contudo não percebe-se uma associação consistente com o nível de disclosure, visto que houve aumento no período 20042006 e começou ter redução após 2006. Desta maneira, assim como já constatado nas outras empresas as características das empresas analisada, não parecem ter relação com a decisão divulgar mais ou menos informações ambientais.

\section{Conclusões e sugestões para futuros trabalhos}

O objetivo deste trabalho foi relacionar o nível de disclosure ambiental com as características das empresas pertencentes ao setor de petróleo e gás com atuação no segmento de biocombustíveis. Os resultados demonstraram que, neste setor, analisando cada empresa individualmente, ao longo dos anos, as variáveis: tamanho, rentabilidade, endividamento, empresa de auditoria e nível de governança não demonstram associação com o nível de disclosure ambiental, ou seja, as empresas da amostra não decidiram aumentar o seu disclosure ambiental simplesmente porque o seu tamanho ou rentabilidade sofreram variação.

Analisando comparativamente, é interessante destacar que a Petrobras, que é a maior empresa da amostra, apresentou maior quantidade de divulgação ambiental, entretanto, ao olhar para as demais empresas percebe-se que a OGX em 2007, apesar de maior que a Ecodiesel apresentou menos informações ambientais, bem como a Ecodiesel apesar de menor que a PetManguinhos apresentou mais informações ambientais.

A adoção ou não de nível diferenciado de governança também não mostrou associação com o disclosure ambiental, visto que a Petrobras que apresentou melhor disclosure não adota nível diferenciado, enquanto a OGX que demonstrou o pior nível de divulgação ambiental pertence ao Novo Mercado.

Desta maneira, a pesquisa demonstrou que individualmente, ao longo dos anos, a relação do nível de disclosure ambiental com as características analisadas, das empresas pertencentes ao setor de petróleo e gás com atuação no segmento de biocombustíveis, não apresentam associação, sugerindo que a decisão de divulgar ou não informações ambientais não depende, do tamanho, rentabilidade, endividamento, empresa de auditoria ou nível de governança.

Com base no estudo realizado, para pesquisas futuras sugere-se a ampliação dos anos pesquisados bem como a inclusão de novas variáveis que poderiam ter relação com o disclosure voluntário ambiental de empresas do setor de biocombustíveis.

\section{Referências}

AKERLOF, George. The market for "lemons": quality uncertainty and the market mechanism. Quarterly Journal of Economics, v. 84, p. 488-500, 1970. 
BOTOSAN, C. A. Disclosure level and the cost of equity capital. The Accounting Review, v. 72, n. 3, p. 323-350, 1997.

BRAMMER, Stephen; PAVELIN, Stephen. Factors influencing the quality of corporate environmental disclosure. Business Strategy and the Environment, vol. 17, p. 120-136, 2008.

BROWN, Alistair, M. Natural environmental disclosures: strategic responses by port moresby stock exchange entities. Business Strategy and the Environment, vol. 16, p. 75-89, 2007.

CALIXTO, Laura; BARBOSA, Ricardo Rodrigues; LIMA, Marilene Barbosa. Disseminação de informações ambientais voluntárias: relatórios contábeis versus internet. Revista Contabilidade \& Finanças (on line), vol. 18, n. spe, p. 84-95, junho 2007. Disponível em: <http://www.scielo.br/pdf/rcf/v18nspe/a08v18sp.pdf>. Acesso em: 04 nov. 2009.

CAMPBELL, David. Intra-and intersectoral effects in environmental disclosures: evidence for legitimacy theory? Business Strategy and the Environment, vol. 12, p. 357-371, 2003.

CHO, Charles H.; ROBERTS, Robin W.; PATTEN, Dennis M. The language of US corporate environmental disclosure. Accounting, Organizations and Society, 2009. doi:10.1016/j.aos.2009.10.002.

FARIAS, Kelly Teixeira Rodrigues; RIBEIRO, Maísa de Souza. A relação entre divulgação ambiental, desempenho ambiental e desempenho econômico nas empresas brasileiras de capital aberto: uma pesquisa utilizando equações simultâneas. In: IAAER-ANPCONT, 3., 2009, São Paulo. Anais... São Paulo: ANPCONT, 2009. CD-ROM.

GRAY, Rob; KOUHY, Reza; LAVERS, Simon. Corporate social and environmental reporting: a review of the literature and longitudinal study of UK disclosure. Accounting, Auditing \& Accountability Journal, vol. 8, nº 2, 1995.

GRAY, Rob; BEBBINGTON, Jan. Accounting for the Environment. 2 ed. Londres: Sage, 2001.

KAENZIG, Josef et al. Using life cycle approaches to enhance the value of corporate environmental disclosures. Business Strategy and the Environment, 2009. DOI: 10.1002/bse.667.

HACKSTON, David; MILNE, Markus, J. Some determinants of social and environmental disclosures in New Zealand companies. Accounting, Auditing \&

Accountability Journal, vol. 9, nº 1, p. 77-108, 1996.

HAHN, Tobias; SCHEERMESSER, Mandy. Approaches to corporate sustainability among german companies. Corporate Social Responsibility and Environmental Management, vol. 13, p. 150-165, 2006.

KOLK, Ans; PEREGO, Paolo. Determinants of the adoption of sustainability assurance statements: an international investigation. Business Strategy and the Environment, 2008. DOI: $10.1002 /$ bse.643. 
KOLK, Ans; PINKSE, Jonatan. The integration of corporate governance in corporate social responsibility disclosures. Corporate Social Responsibility and Environmental Management, 2009. DOI: 10.1002/csr.196.

HOSSAIN, Mohammed. The extent of disclosure in annual reports of banking companies: The case of India. American Accounting Association Annual Meeting, 2008.

LANG, Mark; LUNDHOLM, Russell. Cross-sectional determinants of analyst rating of corporate disclosures. Journal of Accounting Research, v. 31, p. 246-271, 1993.

LEUZ, Christian. Cross listing, bonding and firms reporting incentives: A discussion of Lang, Raedy and Wilson. Journal of Accounting and Economics, v. 42, p. 285-299, 2006.

LEV, B. Information disclosure strategy. California Management Review, v. 34, p. 9-32, 1992.

LIMA, Gerlando Augusto Sampaio de. Utilização da teoria da divulgação para avaliação da relação do nível de disclosure com o custo da dívida das empresas brasileiras. 2007. 118 f. Tese ((Doutorado em Contabilidade e Controladoria) - Curso de Pós-Graduação em Contabilidade e Controladoria, Faculdade de Economia, Administração e Contabilidade, Universidade de São Paulo, São Paulo. Disponível em: $<$ http://www.teses.usp.br/teses/disponiveis/12/12136/tde-26112007-165145/>. Acesso em 18 jan. 2010.

MURCIA, Fernando Dal-Ri et al. 'Disclosure verde' nas demonstrações contábeis: características da informação ambiental e possíveis explicações para a divulgação voluntária. Revista UnB Contábil, vol. 11, nº 1-2, p.260-278, jan./dez. 2008.

NOSSA, Valcemiro. Disclosure ambiental: uma análise do conteúdo dos relatórios ambientais de empresas do setor de papel e celulose em nível internacional. 2002. 249 f. Tese (Doutorado em Contabilidade e Controladoria) - Curso de Pós-Graduação em Contabilidade e Controladoria, Faculdade de Economia, Administração e Contabilidade, Universidade de São Paulo, São Paulo. Disponível em: <http://www.teses.usp.br/teses/disponiveis/12/12136/tde21122005-101506/>. Acesso em: 12 nov. 2009.

PEARCE, D. W., TURNER, R. K. Economics of natural resources and the environment. Baltimore: The John Hopkins University Press, 1989. 378 p.

PERRINI, Francesco; TENCATI, Antonio. Sustainability and stakeholder management: the need for new corporate performance evaluation and reporting systems. Business Strategy and the Environment, vol. 15, p. 296-308, 2006.

RIBEIRO, Alex Mussoi; NASCIMENTO, Letícia Fátima; VAN BELLEN, Hans Michael. Evidenciação ambiental: análise comparativa multissetorial entre Brasil, Estados Unidos e Inglaterra. Contextus - Revista Contemporânea de Economia e Gestão, Fortaleza, vol. 7, n. 1, p. 07-22, jan./jun. 2009.

RICHARDSON, Roberto Jarry. Pesquisa social: métodos e técnicas. 3. ed. São Paulo: Atlas, 2008. 
ROVER, Suliani. Disclosure ambiental de empresas potencialmente poluidoras: características da informação ambiental e explicações para a divulgação voluntária no Brasil. Dissertação (Mestrado) - Universidade Federal de Santa Catarina, Programa de PósGraduação em Contabilidade - Florianópolis, 2009.

ROVER, Suliani; BORBA, José Alonso; MURCIA, Fernando Dal-Ri. Características do disclosure ambiental de empresas brasileiras potencialmente poluidoras: análise das demonstrações financeiras e dos relatórios de sustentabilidade do período de 2005 a 2007. Contextus - Revista Contemporânea de Economia e Gestão, Fortaleza, vol. 7, n. 1, p. 23 36, jan./jun. 2009.

SANTANA, Gean Claudio de Souza. Simulação e análise de custos de produção na produção de biodiesel a partir de óleos vegetais. 2008. 175f. Tese (Doutorado em Engenharia Química) - Faculdade de Engenharia Química, Universidade Estadual de Campinas, São Paulo. Disponível em: <http://libdigi.unicamp.br/document/?code=vtls000448229>. Acesso em: 28 de outubro de 2009.

SILVA, Angelino Fernandes; FERREIRA, Araceli Cristina de Souza. Um estudo sobre a contabilização dos impactos ambientais no setor sucroalcooleiro. In: Congresso USP de Controladoria e Contabilidade, 9., 2009, São Paulo. Anais... São Paulo, 2009.

SILVA, Evandro Mirra de Paula e; SAKATSUME, Fábio. A política brasileira de biocombustíveis. $2007 . \quad$ Disponível em: $<$ http://www.conservacao.org/publicacoes/files/7_Politica_Biocombust_E_Mirra $>$ Acesso em: 14 out. 2009.

SPENCE, Crawford. Social and environmental reporting and the corporate ego. Business Strategy and the Environment, vol. 18, p. 254-265, 2009.

STANNY, Elizabeth; ELY, Kirsten. Corporate environmental disclosures about the effects of climate change. Corporate Social Responsibility and Environmental Management, vol. 15, p. 338-348, 2008.

UHLMANN Vivian Osmari; SOUZA, Maíra Melo; LUNKES, Rogério João. Disclosure Ambiental das Empresas do Setor de Biocombustíveis com Ações listadas na Bovespa: análise das demonstrações financeiras do período de 2004 a 2008. In: SEMINÁRIOS EM ADMINISTRAÇÃO, 13., 2010, São Paulo. Anais... São Paulo: SEMEAD, 2010. CD-ROM.

VELLANI, Cassio Luiz. Disclosure ambiental dos produtores de etanol com ações listadas na BOVESPA e NYSE. Contabilidade, Gestão e Governança, Brasília, vol. 12, n. 1, p. 35-49, jan./abr. 2009. Disponível em: < http://cgg-amg.unb.br/index.php/contabil/article/view/60>. Acesso em: 04 nov. 2009. 